12 Tanner JM. Foetus into man:physical growth from conception to maturity. 2nd ed. Ware, Hertfordshire: Castlemead Publications, 1989.

13 Asher SR, Dodge KA. Identifying children who are rejected by their peers. Dev Psychol 1986;22:444-9.

14 Parkhurst JT, Asher SR. Peer rejection in middle school: subgroup differences in behavior, loneliness and interpersonal concerns. Dev Psychol 1992;28:231-41.

15 Hodges J, Lanyado M, Andreou C. Sexuality and violence: preliminary clinical hypotheses from the psychotherapeutic assessments in a research programme on young sexual offenders. J Child Psychother 1994;20: 283-308.

16 Lanyado M, Hodges J, Bentovim A, Andreou C, Williams B. Understanding boys who sexually abuse other children: a clinical illustration. Psychoanal Psychother 1995;9:231-42.
17 George C, Kaplan N, Main M. Adult attachment interview. Berkely, California: Berkley Department of Psychology, 1985

18 Buss AH, Durkee A. An inventory for assessing different kinds of hostility. J Clin Psychol 1957;21:343-49.

19 Glaser BG, Strauss AL. The discovery of grounded theory: strategies for quali tative research. London: Weidenfield and Nicolson, 1967.

20 Beck AT, Steer RA. Beck hopelessness scale manual. San Antonio, Texas: Psychological Corporation, Harcourt Brace Jovanovich, 1987.

21 Ryan G, Miyoshi TJ, Metzner JL, Krugman RD, Fryer GE. Trends in national sample of sexually abusive youths. J Am Acad Child Adolesc Psychiatry 1996;35:17-25.

(Accepted 6 April 1998)

\title{
Facial structure in the sudden infant death syndrome: case-control study
}

\author{
Karen Rees, Anne Wright, Jean W Keeling, Neil J Douglas
}

The cause of the sudden infant death syndrome is unclear. Polygraphic recordings of 30 infants who subsequently died of the syndrome showed a significant increase in mixed and obstructive apnoeas compared with well matched controls. ${ }^{1}$ Postmortem examination suggests upper airway narrowing in victims of the syndrome. The decreased number of cases of sudden infant death syndrome after advice to put infants to sleep supine suggests a posture dependent cause, and recent evidence suggests that upper airways of sleeping infants are more widely patent supine than prone. ${ }^{2}$ Thus sleeping supine might decrease obstructive apnoeas.

An increased frequency of sudden infant death syndrome and apparent life threatening events in infants has been found in the families of patients with the obstructive sleep apnoea/hypopnoea syndrome. ${ }^{34}$ We found that retroposition of the maxilla was a common feature in families who had both the obstructive sleep apnoea/hypopnoea and sudden infant death syndromes. ${ }^{3}$ We also found that obstructive apnoeas in adult family members of patients with the obstructive sleep apnoea/hypopnoea syndrome were related to retroposition of the maxilla and mandible. $^{5}$

We therefore tested the hypothesis that victims of the sudden infant death syndrome have backset maxillae and mandibles, which would predispose them to narrowing and occlusion of their upper airways.

\section{Subjects, methods, and results}

We examined differences in facial bone structure between 15 consecutive victims of the sudden infant death syndrome and 15 control infants who had died of explained causes. Each case was matched to a control infant aged within one postnatal month of the case (mean age 5 months, range 1-10 months). Lateral cephalographs taken at necropsy were examined for the maxillary position (the sella-nasion-subspinale angle) and the mandibular position (the sella-nasionsupramentale angle) (figure). These two angles have been shown to differ between first degree relatives of patients with sleep apnoea and the normal population. ${ }^{5}$ Measurements were recorded twice for each sub-

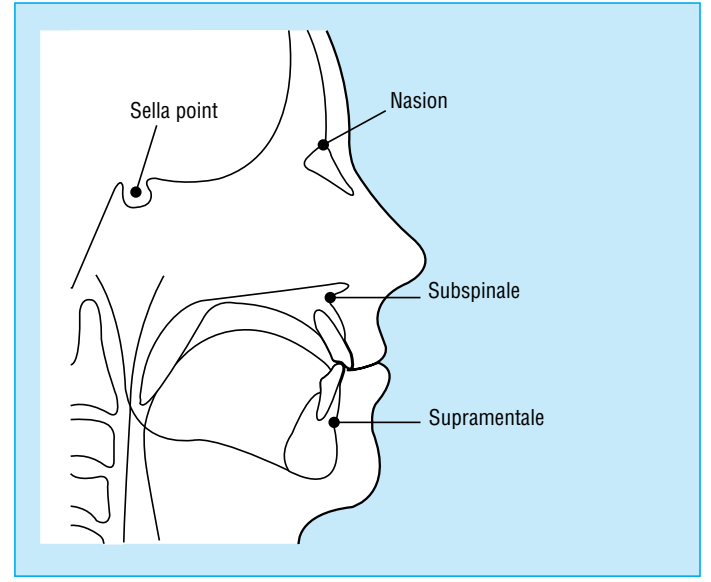

Skeletal reference points on schematic lateral cephalometric radiograph. Sella point is the midpoint of the sella turcica, the nasion is the most anterior point of the frontonasal suture, the subspinale is the most posterior point on the anterior contour of the upper alveolar process, and the supramentale is the most posterior point on the anterior contour of the lower alveolar process

ject by one observer blind to cause of death, and the average values were taken. The coefficient of variation for repeat measurements within individuals was $0.4 \%$ (range $0-1 \%$ ) for the maxillary angle and $0.4 \%(0-2 \%)$ for the mandibular angle. Differences between cases and controls were determined with Wilcoxon's rank sum test for paired differences. Significance was taken as $\mathrm{P}<0.05$.

There was no difference in body weight between the cases and controls (5.7 kg (SE 1.0) v $5.7 \mathrm{~kg}(0.5))$. The cases had significantly smaller maxillary angles than the controls (median $82^{\circ}(95 \%$ confidence interval $79^{\circ}$ to $\left.85^{\circ}\right) v 84^{\circ}\left(83^{\circ}\right.$ to $\left.\left.90^{\circ}\right), \mathrm{P}=0.01\right)$. There was a trend for the mandibular angle to be smaller in the cases than in the controls $\left(71^{\circ}\left(67^{\circ}\right.\right.$ to $\left.74^{\circ}\right) v 75^{\circ}$ $\left(70^{\circ}\right.$ to $\left.\left.77^{\circ}\right), \mathrm{P}=0.1\right)$.

\section{Comment}

This study shows that victims of the sudden infant death syndrome had different facial structure compared with control infants, with retroposition of the
Respiratory

Medicine Unit, Department of Medicine, University of Edinburgh, Royal Infirmary, Edinburgh, EH3 9YW

Karen Rees, research associate Neil J Douglas, professor of respiratory and sleep medicine

Department of Paediatric Pathology, Department of Medicine, University of Edinburgh Anne Wright, chief medical laboratory scientific officer Jean W Keeling, consultant paediatric pathologist

Correspondence to: Professor Douglas n.j.douglas@ed.ac.uk

BMJ 1998;317:179-80 
maxilla that might predispose to retropalatal upper airway narrowing. Since facial structure is at least partly inherited, this may provide the familial link in the sudden infant death syndrome, although larger studies are required to confirm these findings. These results also provide a further link between the sudden infant death and obstructive sleep apnoea/hypopnoea syndromes, as the facial changes are similar in both conditions.

Our study indicates that a retrognathic facial structure should be considered as an additional risk factor for the sudden infant death syndrome, and the suggested mechanism for upper airway narrowing could also contribute to the posture dependence of the syndrome and to the association with upper respiratory tract infections, which predispose to obstructive apnoeas by increasing nasal resistance. We suggest there is a need to assess whether prevention of obstructive apnoeas, such as by continuous positive airway pressure, prevents the sudden infant death syndrome in high risk infants.
Contributors: KR measured all the radiographs and participated in the design of the study and in writing the article. NJD participated in the design of the study, data analysis, and in writing the article. AW took the radiographs and participated in writing the article. JWK performed all the necropsies and participated in the design of the study and in writing the article. NJD is guarantor for the article.

Funding: KR was funded by ResMed during this study. Conflict of interest: None.

1 Kahn AA, Groswasser J, Rebuffat E, Sottiaux M, Blum D, Foerster M, et al. Sleep and cardiorespiratory characteristics of infant victims of sudden death: a case control study. Sleep 1992;15:287-92.

2 Skatvedt O, Grogaard J. Infant sleeping position and inspiratory pressures in the upper airways and oesophagus. Arch Dis Child 1994;71:138-40.

3 Mathur R, Douglas NJ. Relationship between sudden infant death syndrome and adult sleep apnoea/hypopnoea syndrome. Lancet 1994:334:819-20

4 Tishler PV, Redline S, Ferrette V, Hans MG, Altose MD. The association of sudden unexpected infant death with obstructive sleep apnea. Am J Respir Crit Care Med 1996;153:1857-63.

5 Mathur R, Douglas NJ. Family studies in patients with the sleep apnoea hypopnoea syndrome. Ann Intern Med 1995;122:174-8.

(Accepted 27 February 1998)

\title{
Disease activity and risk of lymphoma in patients with rheumatoid arthritis: nested case-control study
}

\author{
Eva Baecklund, Anders Ekbom, Pär Sparén, Nils Feltelius, Lars Klareskog
}

Department of

Medicine,

University Hospital,

S-751 85 Uppsala,

Sweden

Eva Baecklund,

rheumatologist

Nils Feltelius,

associate professor

Department of

Medical

Epidemiology,

Karolinska Institute,

Box 281, S-171 11

Stockholm, Sweden

Anders Ekbom,

associate professor

Pär Sparén,

statistician

Department of

Medicine,

Karolinska Hospital,

S-171 76

Stockholm, Sweden

Lars Klareskog,

professor

Correspondence to:

Dr Baecklund

Eva.Baecklund@

swipnet.se

BMJ 1998;317:180-1
Inflammatory diseases such as rheumatoid arthritis and their treatment may have a pathogenic relation with cancer. The possible relation also has practical implications for the care and control of rheumatic patients.

Patients with rheumatoid arthritis have been shown to have an increased risk of developing lymphomas. ${ }^{12}$ The underlying mechanisms for this association are unclear. We performed a study to assess to what extent disease activity, various secondary manifestations of rheumatic disease, and drug treatment were independent risk factors for the development of lymphoma in patients with rheumatoid arthritis.

\section{Subjects, methods, and results}

We performed a nested case-control study using a previously described population based cohort of all patients admitted to hospital with rheumatoid arthritis during 1965-83 in Uppsala health care region, Sweden. ${ }^{3}$ We identified 42 cases of lymphoma in the 11683 patients with rheumatoid arthritis through record linkages with the Swedish cancer registry. Cases were individually matched to three controls from the same rheumatoid arthritis cohort. All medical records were reviewed and data, including disease manifestations and treatment from the first symptoms compatible with rheumatoid arthritis until the date of the diagnosis of the lymphoma in the case, were abstracted for cases and controls. All cases and controls were evaluated to assess if the 1987 American College of Rheumatology criteria for rheumatoid arthritis were met, and patients not having rheumatoid arthritis were excluded. The risk of lymphoma was measured as unadjusted and adjusted odds ratios. The study finally consisted of 41 cases and 113 controls.

The table gives exposures linked to an increased risk of lymphoma together with the unadjusted odds ratios. High inflammatory activity was the most prominent risk factor for development of lymphoma, with an odds ratio of 25.8 compared with low inflammatory activity. Inflammatory activity was estimated by a score comprising the whole period of rheumatoid arthritis disease and was based on available data on erythrocyte sedimentation rates, number of swollen and tender joints, and the treating physician's global assessment of disease activity. Other exposures associated with disease severity also entailed an increased odds ratio for lymphoma, such as functional class IV of Steinbrocker (odds ratio 12.9), widespread joint involvement (odds ratio 9.3), and certain extra-articular symptoms.

Few patients were treated with immunosuppressive drugs, reflecting the standard treatment during the study period. Non-steroidal anti-inflammatory drugs, aspirin, and corticosteroids were in common use, but only a few patients were treated with antimalarials, parenteral gold, D-penicillamine, podophyllotoxin, or sulphasalazine.

We found no association between any specific drug and increased risk of lymphoma. Once drug treatment was adjusted for there was a strong independent 